\section{Allergy Immunology}

\title{
Associate Editor Thomas Schwarz
}

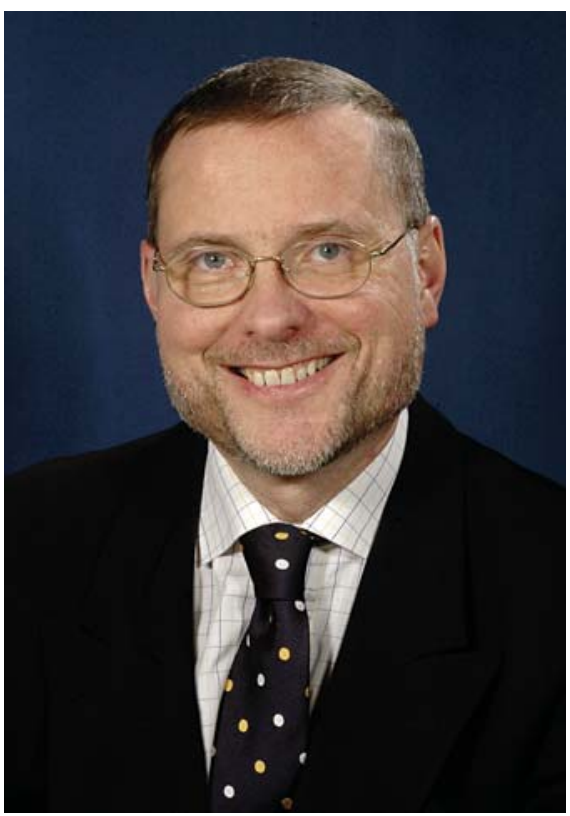

Thomas Schwarz, Kiel.
Thomas Schwarz, MD, is Professor and Chairman of the Department of Dermatology and Allergology, Christian Albrecht University of Kiel, Germany. After studying medicine at the University of Vienna, he graduated with an $\mathrm{MD}$ and received his training as a dermatologist in Vienna, Austria. He went on to hold a number of clinical and research positions in Austria, Germany and the USA. In 2004, he took up his current position at the University of Kiel where he is now Chairman of the Department of Dermatology. His clinical activities focus on chronic inflammatory dermatoses, skin cancer and photodermatology. In his basic research activities Dr. Schwarz is studying the effects of UV radiation on the immune system and UV-induced signal transduction. Professor Schwarz is a member of key societies in the dermatology, immunology and photobiology fields and served on the editorial panels for various peer-reviewed journals including The Journal of Investigative Dermatology, Photochemistry and Photobiology, Photodermatology, Photoimmunology and Photomedicine, and International Archives of Allergology and Immunology. He was President of the European Society for Dermatologic Research (ESDR) from 2005 to 2006. From 2007 to 2012, he served as Vice-Dean of the Medical Faculty of the University of Kiel. 